\title{
Hypothermia after decompressive hemicraniectomy in treatment of malignant middle cerebral artery stroke: comment on the randomized clinical trial
}

\author{
N. Engrand ${ }^{1 *}$, M. Mazighi ${ }^{2}$ and V. Dinkelacker ${ }^{3}$
}

Therapeutic hypothermia $(\mathrm{TH})$ is currently evaluated in acute brain injury of diverse etiologies. In the clinical trial DEPTH-SOS, Neugebauer et al. [1] reported negative results for $\mathrm{TH}\left(33 \pm 1^{\circ} \mathrm{C}\right)$ in malignant acute ischemic stroke (AIS) in adjunction to decompressive hemicraniectomy. TH improved neither survival at day 14 or at 12 months, nor long-term functional outcome. Instead, severe adverse events (SAE) in the TH-group entailed premature trial discontinuation. We revisit the study design with regard to its clinical objectives.

$\mathrm{TH}$ may have two objectives in acute brain injury: intracranial pressure (ICP) control or neuroprotection. Regarding ICP control, it is the relative hypocapnia due to hypothermia which allows an ICP decrease, and hypocapnia will therefore be tolerated (alpha-stat principle) [2]. For the aim of neuroprotection, hypothermia-induced hypocapnia is counterbalanced with respirator settings modification (minute volume decrease) in order to restore normocapnia (pH-stat principle) [3]. Accordingly, studies assessing neuroprotection while capnia management was based on the alpha-stat principle have shown no positive effects [4].

In the case of AIS, the choice of either of these strategies depends on the clinician's objective.

Indeed, the alpha-stat management allows ICP control and thus prevents reperfusion hyperemia as a source of hemorrhagic transformation, while the $\mathrm{pH}$-stat management ameliorates neuroprotection in the penumbra area.

In the DEPTH-SOS trial, TH was performed to obtain ICP control as adjunctive therapy to decompressive hemicraniectomy, but failed to prevent early mortality from malignant AIS.
In our opinion, a major reason for this failure is that $\mathrm{PaCO} 2$ was obviously managed according to the $\mathrm{pH}$-stat principle (although it is not specified), since ICP was superior in the $\mathrm{TH}$-group compared to the control group during the $\mathrm{TH}$ period. The $\mathrm{pH}$-stat management may have also contributed to excess SAE in the TH group, since it induces relative hypercapnia (given the hypothermia) and therefore increases reperfusion hyperemia with its inherent deleterious effects.

Finally, TH was effective rather late, over $48 \mathrm{~h}$ after AIS and most often after vascular recanalization, i.e., with a reperfused penumbra area. In this scenario, the $\mathrm{pH}$-stat management has only limited impact on neuroprotection.

After an AIS reperfusion, it is crucial to control $\mathrm{PaCO} 2$ and arterial blood pressure to closely match cerebral blood flow $(\mathrm{CBF})$ to oxygen requirements. The goal should be to provide the minimum $\mathrm{CBF}$ needed in healthy territories, in order to limit hyperemia in infarcted territories, through suitable monitoring (transcranial Doppler, or brain tissue oxygen partial pressure measurement).

In conclusion, this study pools patients with different characteristics of hemodynamics and brain injury, which limits the interpretation of the findings. An individually targeted TH approach, based on carefully monitored cerebral hemodynamics, may be more appropriate for AIS patients. Hence, TH should not be systematically discarded in AIS, but its management should be adapted to the individual patient's profile. This study illustrates once more how neuroprotective strategies fail due to inappropriate timing and treatment objectives.

\footnotetext{
* Correspondence: nengrand@for.paris

${ }^{1}$ Neuro-Intensive Care Unit, Fondation Ophtalmologique Rothschild, 29 rue

Manin, 75019 Paris, France

Full list of author information is available at the end of the article
} 


\section{Acknowledgements}

None

\section{Funding}

None

Availability of data and materials

Not applicable for that section.

\section{Authors' contributions}

The three authors drafted together the letter. All authors read and approved the final manuscript.

\section{Ethics approval and consent to participate}

Not applicable for that section.

\section{Consent for publication}

Not applicable for that section.

\section{Competing interests}

The authors declare that they have no competing interests.

\section{Publisher's Note}

Springer Nature remains neutral with regard to jurisdictional claims in published maps and institutional affiliations.

\section{Author details}

${ }^{1}$ Neuro-Intensive Care Unit, Fondation Ophtalmologique Rothschild, 29 rue Manin, 75019 Paris, France. ${ }^{2}$ Interventional Neuroradiology Department, Fondation Ophtalmologique Rothschild, 29 rue Manin, 75019 Paris, France. ${ }^{3}$ Neurological Department, Fondation Ophtalmologique Rothschild, 29 rue Manin, 75019 Paris, France.

Received: 28 March 2019 Accepted: 18 April 2019

Published online: 09 May 2019

\section{References}

1. Neugebauer $H$, Schneider $H$, Bösel J, et al. Outcomes of hypothermia in addition to decompressive hemicraniectomy in treatment of malignant middle cerebral artery stroke: a randomized clinical trial. JAMA Neurol. 2019. https://doi.org/10.1001/jamaneurol.2018.4822.

2. Vigué $B$, Ract $C$, Zlotine N, et al. Relationship between intracranial pressure, mild hypothermia and temperature-corrected $\mathrm{PaCO} 2$ in patients with traumatic brain injury. Intensive Care Med. 2000;26:722-8.

3. Voicu S, Deye N, Malissin I, et al. Influence of a-stat and pH-stat blood gas management strategies on cerebral blood flow and oxygenation in patients treated with therapeutic hypothermia after out-of-hospital cardiac arrest: a crossover study. Crit Care Med. 2014;42:1849-61. https://doi.org/10.1097/ CCM.0000000000000339.

4. Ebner F, Harmon MBA, Aneman A. Carbon dioxide dynamics in relation to neurological outcome in resuscitated out-of-hospital cardiac arrest patients: an exploratory Target Temperature Management Trial substudy. Crit Care. 2018;22:196. https://doi.org/10.1186/s13054-018-2119-5 